\title{
Pre-service Teachers' Reflection on Reflective Practices: A Malaysian Perspective
}

\author{
S. Chee Choy, Joanne Sau Ching Yim, Daljeet Singh Sedhu*
}

\begin{abstract}
Research Centre for Educational Psychology and Instructional Strategies, Tunku Abdul Rahman University College (TARUC) Perak Branch Campus, Malaysia
\end{abstract}

Received September 3, 2019; Revised November 24, 2019; Accepted December 3, 2019

Copyright@2019 by authors, all rights reserved. Authors agree that this article remains permanently open access under the terms of the Creative Commons Attribution License 4.0 International License

\begin{abstract}
This study aimed to explore the use of reflective thinking practices incorporated into classroom teaching by pre-service teachers (PSTs). Firstly, this study investigated the reflective thinking practices used by PSTs to analyse their teaching strategies and approaches in the classroom. Secondly, this study explored the ways PSTs use reflective thinking to analyse their teaching practice. The qualitative method employing semi-structured interviews was used in this study. A sample of 11 female final year PSTs enrolled in Bachelor of Education programmes in a Malaysian university, who had just completed their 16-week teaching practicum that was selected as the participants of this study. The data were analysed using the interpretive approach in order to allow the PSTs to voice their reflective thinking experiences. Analysis of the data yielded seven categories: Opportunities to reflect, Expression of feelings, Teaching awareness, Lifelong learning, Self-confidence, Self-assessment, and Self-belief. Overall, the findings of this study indicated positive perceptions by the PSTs about using reflective practices to help them teach. However, the findings also showed that the reflection carried out by the PSTs favoured the technical and practical levels rather than being able to critically analyse their own teaching process. The results also indicated that the PSTs were not open to negative feedback given by students, as they were looking more towards the popularity factor and acceptance from students than learning from the experience as a whole. A major implication of the present study was that Malaysian PSTs may not know how to effectively use reflective thinking to help them improve their teaching skills at the same time cultivate critical thinking. They seemed to focus more on being evaluated well by their mentors than the learning that occurred during their lessons.
\end{abstract}

Keywords Reflective Practices, Reflective Thinking, Pre-service Teachers

\section{Introduction}

Developing pre-service teachers' (PSTs) ability to carry out critical and deep thinking has been the essential goal for learning and transformation in the Malaysian education system as stated in the Malaysian Education Blueprint (MEB) (Ministry of Education Malaysia, 2013). Felton and Kuhn (2007) further note that critical thinking, which is the process of analysing and evaluating something in order to form a judgement, requires considerable effort and students will engage in the cognitively complex process only if they reflect on it and perceive it is worth the effort. Hence, the function of reflective thinking is to make meaning and formulate relationships between learning experiences and create continuities which Rodgers, (2002) notes is an important step to the process of critical thinking.

A critical point Dewey (1963) noted is that once students direct their attention to learn and perceive a fact, it is often limited by the context they are in and this is especially true in a classroom setting. The role of the teacher is to step in to stimulate reflection of the fact and to perceive more rather than less. Hence, it is crucial for teachers to have the skills to carry out reflective thinking themselves and eventually become a model demonstrating the process of such thinking. However, this is not the case as research has shown that teachers themselves often do not know how to be reflective or demonstrate reflective thinking (Black, 2005; Choy \& Cheah, 2009; Choy \& Oo, 2012; DeWitt, Alias \& Siraj, 2016).

According to DeWitt et al. (2016) critical thinking skills have been incorporated into the Malaysian school syllabus since 1994 and teachers have been trained in strategies to teach critical thinking during their pre-service courses using the infusion approach where every teacher is required to use teaching-learning methods and techniques which will stimulate, encourage, and develop the thinking abilities of students (Kuldas, Hashim \& Ismail, 2015). DeWitt et al (2016) further noted that Malaysian teachers tended to teach facts, implying surface learning rather than incorporate the 
use of arguments into their lessons which involved reflective and deep thinking. These teachers also tended to use analogies which can result in lower levels of thinking among students because of insufficient prior knowledge of the subject matter to stimulate critical and deep thinking. In the MEB it was stated that a 2011 research study found that only 50 per cent of the lessons in schools are being delivered effectively where students are sufficiently engaged and actively participate in their lessons. Further to this, much of the lessons in Malaysian classrooms focused on surface-level content understanding instead of deep thinking skills. The same report also stated that this practice among teachers is a challenge for Malaysia as 60 per cent of its current teachers will still be teaching for the next 20 years. In view of these challenges, there is a definite need for effective skills to stimulate thinking in classrooms, as well as determine the use of and the effectiveness of reflective thinking skills incorporated during teacher training in bringing about the interpretation of skills needed to enhance future interactions within the classroom. Hence two research questions underpin this study:

1. What are the reflective thinking practices used by PSTs to analyse their teaching strategies and approaches in the classroom.

2. How do PSTs use reflective thinking to analyse their teaching practice.

\section{Literature Review}

\subsection{Reflective Thinking}

Teaching is complex requiring a degree of self-reflection and ability to apply situation-specific solutions in classroom settings. It is necessary for a teacher to not only have professional knowledge that is gained outside the classroom but also an ability to interpret their everyday experiences from within the classroom (Sparks-Langer \& Colton, 1991). Barnhart and van Es (2015) found in their study that teachers who used reflective thinking to interpret the nuances of their students' actions allowed them to respond appropriately to their students' needs as well as use teaching as a learning profession, where they learn from their practice over time. Teachers who were asked to reflect on their teaching found it to be helpful in problem solving and problem resolution (Hayden \& Chiu, 2015). With the call of the Malaysian government to develop critical thinking in students as one of the six attributes to be attained, a definition of critical thinking in line with the current skills and needs of these students has to be examined.

Rather than being a solitary undertaking, critical thinking has now been redefined by Kuhn (2016) to have shifted more to a form of social practice where it is embedded into actual and virtual contexts of others and whose reactions need to be analysed, reflected on and are evaluated constantly. Hence, students are constantly challenged to carry out reflective thinking on situations they are in, where individual competencies are situationally guided to a certain degree requiring continued reflection in order to assess and understand the situation. Teachers who use reflective thinking know something about the effects they have on students. They are alert to the presence of power in their classroom and the possibility for misuse, and knowing their actions can silence or activate students' voices (Brookfield, 1995). Individuals who are reflective about what they are doing also had fewer errors and learned more in their work compared to non-reflectors (Lindh \& Thorgren, 2015; Roessger, 2014). Schon (1987) suggested that the capacity to reflect on action so as to engage in a process of continuous learning is one of the characteristics of active learning. The cultivation of reflection in action while doing something and the reflection on action after doing it is an important feature in many learning situations where students are asked appropriate questions by their teachers to ensure they constantly reflect on what they are doing. However, the distinction between the two types of action is far from clear as Schon had highlighted (Clara, 2014). Osterman and Kottkamp (1993) proposed a model for reflective thinking for educators which aims to bring about such behavioural changes to teaching practices through self-awareness. The model proposes that teachers can personalise content to share with learners who become agents for change in their environment. The teachers are constantly reflecting on their practices and acts as facilitators for learning. Sahin and Ovez (2012) also found that the reflective tendencies of teachers changed over time depending on the type of schools and the subjects they were teaching.

\subsection{Teaching Deep Thinking and Problem Solving Skills}

The lack of deep thinking skills will have implications for problem-solving skills. Naggapan (2001) noted that incorporating deep thinking into the curriculum for all students poses challenges as there is adequate research that suggests a need to explicitly infuse this form of thinking into the content being taught. Apart from this, Naggapan also found that in order for the acquisition of deep thinking skills to be successful, factors that involve the teachers also need to be taken into consideration. These factors include but are not limited to teachers' knowledge, skills and attitudes, continuous professional development of teaching skills, framework for teaching thinking, and the terminology and taxonomy needed for teaching thinking.

Naggapan (2001) further noted the role of teachers is to improve the quality of students' thinking and not necessarily teach them how to think. Consideration must also be given to the fact that the creative and critical thinking abilities of individuals may not improve as they mature. According to Ennis (2011), many students are not able to think critically and carry out deep thinking because they do not have the criteria for carrying out these forms of thinking and teachers often do not promote deep thinking to them. Hence, the MEB's call for developing students' critical and creative thinking will require some innovative moves in teaching 
approaches and strategies. Ong (2006) suggested that student feedback on their experiences when learning deep thinking skills will be crucial to help teachers reflect on their teaching approaches and strategies.

Ennis (2011) criticised Bloom's (1956) taxonomy for its inability to promote critical, deep or reflective thinking through its different levels because these levels are often confusing and the teachers themselves cannot differentiate between them (Nagappan, 2001). Further to this, Choy, Yim and Tan (2017) in a study of 1070 Malaysian PSTs found that reflective thinking is significantly influenced by self-belief, teaching awareness, and self-assessment ability. However, the same study also found that these teachers were not able to carry out continuous assessment and evaluations of teaching strategies and the influences they have on student learning. This will have implications on the ability of Malaysian PSTs to use effective teaching strategies to stimulate their students' critical and creative thinking suggesting that Malaysian PSTs are reflective only on aspects of their teaching that do not require critical analysis and forethought. Wong, et al (2015) similarly found in their study that Malaysian PSTs do not use critical thinking which questioned the underlying moral and ethical dimension of decisions made during teaching and self-reflection. The thinking used mainly focused on teaching strategies and personal preferences, with some focus on reflecting the underlying assumptions of teaching practices. Hence these PSTs do not have the experience to stimulate and promote the level of critical thinking among their students as aspired in the MEB. It is crucial that reflective thinking, which is thought by many researchers (Choy, Yim \& Tan 2017; Lindh \& Thorgren, 2015; Barnhart \& van Es, 2015; Ennis,2011)is to promote critical thinking, is studied with greater detail and more in-depth to help facilitate this form of thinking among Malaysian PSTs.

\section{Methodology}

\subsection{Data Collection}

Final year PSTs enrolled in Bachelor of Education programmes who had just completed their 16-week practicum teaching in a Malaysian university were invited to participate in the study. A final sample of 11 female PSTs was selected to be interviewed based on recommendations from their lecturers that they were able to express and converse well in English. The goal was to have a sample of the student population that meet the specific needs of this study (Cohen, Manion \& Morrison, 2000). A list of interview questions is included as appendix 1. All the PSTs were interviewed using a semi-structured approach because as Wragg (1984), p.184 puts it:

'[ . . ] a semi-structured interview tends to be one of the most favoured by educational researchers as it allows respondents to express themselves at some length, but offers enough shape to prevent rambling.'
It also reduces incidences of interviewer bias, and increases comparability of responses and ensures data that are complete for each respondent on the topics addressed. Each interview lasted approximately 30 minutes and was recorded. The informed consent of each respondent was obtained and they were told they could leave the study at any time they wished. They were also told that the information provided will be kept confidential and their anonymity maintained. The respondents were not given inducements of any kind to participate.

\subsection{Profile of Sample}

The 11 PSTs that participated in the interviews were enrolled in the Bachelor of Education programmes in the Teaching English as a Second Language programme. These PSTs were all females in their fourth year of studies and were aged between 22 and 23 years. There are no male representatives in the sample as no male pre-service teacher volunteered to be interviewed.

\subsection{Context of the Experience}

The 11 respondents had completed their four months teaching practicum and was completing the final semester of their bachelor programme. The practicum course is designed to provide opportunities for PSTs to have hands-on experience in the classroom. Each respondent was assigned a mentor teacher and a supervisor during the practicum and had to write a reflective report of the practicum experience.

\subsection{Analysis}

The data were analysed using the interpretive approach because this study is about giving voice to PSTs' reflective thinking experiences (Larkin, Watts \&Clifton, 2006). The intention is not to oversimplify the voices of individuals by summarising their opinions but rather to develop them at an interpretive level. This approach required firstly, an intensive and detailed analysis of accounts produced by the participants which were captured verbatim and secondly, an in-depth and analytical commentary on their 'sense-making' activities when learning. Therefore the interpretivist knowledge is contestable precisely because it represents an intertwining of facts and values.

\section{Results and Findings}

Analysis of PSTs interviews yielded seven main categories as shown in Table 1: opportunities to reflect, expression of feelings, teaching awareness, lifelong learning, self-confidence, self-assessment and self-belief. The frequency is from positive and negative salient points which made reference to the categories in the interviews. The spaces are left blank if there are no comments belonging to the category. 
Table 1. Analysis of PSTs interviews

\begin{tabular}{llcr}
\hline \multirow{2}{*}{ Category } & \multicolumn{1}{c}{ Definition } & \multicolumn{2}{c}{ Frequency } \\
\cline { 2 - 3 } Opportunities to reflect & Occasions favourable for carrying out reflective thinking & Positive & Negative \\
\hline Expression of feelings & $\begin{array}{l}\text { Voicing and articulation of feelings toward students and } \\
\text { classroom situations }\end{array}$ & 11 & 11 \\
\hline Teaching awareness & $\begin{array}{l}\text { The process of gaining insights into one's own teaching } \\
\text { abilities. }\end{array}$ & 11 & 11 \\
\hline Lifelong learning & $\begin{array}{l}\text { Intentions to learn more about teaching and the processes } \\
\text { involved. }\end{array}$ & 10 & 6 \\
\hline Self-confidence & $\begin{array}{l}\text { Reflections on one's own teaching abilities leading to } \\
\text { improvements and eventual mastery of the skill. }\end{array}$ & 5 & 11 \\
\hline Self-assessment & $\begin{array}{l}\text { Procedure to systematically reflect, analyse and value } \\
\text { one’s professional actions and its result in order to } \\
\text { improve it. }\end{array}$ & 5 & 11 \\
\hline Self-belief & Confidence in one's own teaching abilities. & \\
\hline
\end{tabular}

\subsection{Opportunities to Reflect}

Eight of the respondents had positive comments about opportunities to reflect on their teaching especially during their practicum as they had to write their reflective journals. However, most of the reflections that were carried out seemed to favour delivery of lesson and effectiveness of their teaching strategies. For instance PST A said,

"For me I try to reflect on my teaching after every class and whether the activities conducted in class were effective for students or not. I will reflect to see if the materials I used were suitable for all levels of students."

Three of the respondents commented they had to reflect on their teaching practices and were more likely to carry out reflective thinking during practicum as they had to write the reflective journal. They were less positive about carrying out reflective thinking when writing the journal as they felt stressed about having to ensure their teaching was of good quality and wanted to know how they were performing from their mentors. They preferred immediate feedback rather than reflect for themselves. For instance PST C said,

"I usually want to write my reflective journals after I finish teaching so that it is fresh in my mind. I have also started writing a diary so that I can record my thoughts. I feel pressured because I want to know how I did in my teaching and if my students can understand and follow what I did. I want to catch any teaching problems and identify students' problems. It is better and faster to ask my mentor than analyse my reflective journal.”

\subsection{Expression of feelings}

All the respondents commented that they felt a need to reflect on how to influence the thinking of their students. They perceived that many of their students did not show interest to learn in school because they were not properly influenced by their teachers when they were young. They felt positive about being able to influence their students' thinking.
For instance PST E commented,

"I teach English and many of my students do not like the subject because they think it is hard. I feel that I need to reflect on how to influence the way they think and help them learn the language better. I want to instil moral values in them so that they can grow up to be well developed people."

These respondents also expressed feelings of worry about the way they teach. They seemed most worried and reflected mostly about not being effective in class because their lessons may not be differentiated enough to meet the needs of students with different ability levels. For instance PST B commented,

"I worry my students cannot understand me and they get confused about what they are learning. My students are from different ability levels and my lessons may not be differentiated enough to cater to the needs of all of them. I reflect on this constantly.”

\subsection{Teaching awareness}

All the respondents perceived that the reflective thinking process required when writing their journals allowed them to get to know more about their teaching abilities. However, many of the experiences related by the respondents focused on their own performance as teachers rather than the actual learning and incidences that took place in the classroom. All of them mentioned that they were more concerned about how students perceived their teaching rather than students' perceptions of the materials they were presenting. For example PST H said,

"My main concern in class is about my performance as a teacher. The students do not participate in my class and I am worried that they do not understand what I am teaching them. I do not want them to switch off and not listen to my lesson. I also feel like how I act in class is also very important as this will help keep my students' interest in class.” 


\subsection{Lifelong learning}

Ten of the respondents perceived they were continuously cultivating and improving their teaching skills. They perceived they continued to learn through meaningful interactions with their students and also through upgrade of their professional qualifications. For instance PST E said,

"For me I feel that learning is a lifelong process and it continues even after you finish university. I have plans to do my master degree after I finish with my current bachelor but not right away. I need to gain some experience first before I start on my next degree.”

It must also be noted that apart from pursuing higher degrees these respondents did not perceive everyday life experiences in classrooms as contributing to lifelong learning. PST G said,

"I want to pursue my master degree like my sister. Formal education will help increase my lifelong learning. When I went for my practicum, I guess was also given lifelong learning experience as I was allowed to do hands-on practicum. I guess the opportunities for learning have been limited in my opinion to formal settings. I do not think I have lifelong learning when I teach my students because it is like practical. Putting theory to action.”

\subsection{Self-confidence}

Five of the respondents were enthusiastic about reflecting on their teaching in order to improve their teaching skills. However the focus of their reflections was mainly on how to get students to like their teaching and to get students to be more participative in class. For instance PST H said,

"I do reflect on my teaching because I am worried how the students perceive my teaching. I want to influence the way my students think about learning English. I think there must be more to just going to class and listening. It gives me confidence when I can get students to interact with me and not just sit and listen. I do not know what they are thinking about then. Whether they understand me or not.”

Six of the respondents felt they were not as self-confident as they should be, especially during their practicum. They were not confident about establishing rapport with students as they were unsure if they had planned their lessons well. For instance PST J said,

"I am not as self-confident as I should be especially during my practicum as I do not know if I prepared my lessons well. My students sometimes do not interact with me in class and I do not know what they think of my lessons.”

It interesting to note that all the respondents were more interested in their own performance as a teacher than the learning that takes place in the classroom. The reflection of their practice also focused on delivery of lessons rather than the actual learning that was taking place in the classroom.

\subsection{Self-assessment}

Only five respondents stated that they assessed themselves based on the feedback and comments gathered from students. These respondents also shared that they used videos of themselves teaching and their reflective journals as tools to evaluate their teaching and determine if they were effective in the classroom. For instance PST G said,

"I will record myself in order to watch how I teach so that I can evaluate my teaching skills and strategies. I will also use the reflective journals as a way to evaluate myself as well. I will look to improve my lesson presentation and mistakes I had made from the videos and not repeat the same mistakes again.”

Six respondents commented that while they did write reflective reports, they tended to depend on their friends and mentor teachers to advise them on their teaching. They prefer the opinions of others to help improve their teaching rather than analyse their reflective journals. For instance PST I said,

"Writing the reflective is a must during practicum. I have been advised by my supervisor to make a video of myself teaching to help me evaluate myself. However, I still prefer to ask the opinions of my mentor teachers and friends that I trust to give me feedback about my teaching."

\subsection{Self-belief}

All the respondents believed they had good teaching abilities and were willing to learn from the feedback obtained from students. They also believed that their life experiences had contributed to the way they teach and deal with students. Although all of them admitted they had a difficult time dealing with negative feedback from students and had in some moments doubted their ability to teach. For instance PST J said,

"I believe that the way I handle students has come from the way I was influenced by my caretakers and elders in my life. I have always believed that you learn from life experiences. That has built my confidence. However, it is hard when students give me negative feedback and I have a hard time trying to figure out what I had done wrong. That worries me and can also be stressful.”

\section{Discussion}

The discussion will focus on using the results obtained to answer the two research questions.

1. What are the reflective thinking practices used by teachers to analyse their teaching strategies and approaches in the classroom?

On the whole the results showed that PSTs were positive about using reflective practices to help them with their teaching. However, the results also indicate that the reflection carried out by the PSTs was more on the technical 
and practical levels rather than critically analysing their teaching processes (Yaacob et al, 2014). The technical level focuses on the teacher and the success and failure of the techniques used, the practical level focuses on students' learning experiences and examination of strategies used and the critical level is where the teacher begins to question how the environmental context influences the way students learn. They were on the whole more concerned about how they were teaching than what their students were learning similar to findings by Nair and Ghanaguru (2017). As far as opportunities to carry out reflective thinking, most of the respondents were positive about this because they had to write their reflective journals as part of the course requirements. However some of them were unsure if they will continue with this practice when they are practicing teachers. This seems to indicate that these PSTs have not grasped the idea that reflective thinking practices are meant to make meaning and create a relationship with their learning experiences and other experiences in the classroom to create continuity (Rodgers, 2002) which can further enhance their teaching skills as well as develop critical thinking skills. Therefore the aim of the Malaysian government to promote critical thinking in students may not be achievable unless teachers are able to think critically themselves and it has to begin with them reflectively thinking about their classroom experiences.

The respondents expressed concerns about their ability to influence and control their students with specific mention of moral values by some of them. This seemed to concern all the PSTs indicating a need to control their students in terms of their behaviour and thinking rather than influence their ability to think and learn on their own. Although studies (Barnhart \& van Es, 2015; Yaacob et al.; 2014) have found that teachers reflecting on and assessing their own teaching have helped in problem solving and responding to students appropriately, these PSTs seemed more intent on controlling the classroom and student behaviour. Suggesting that these PSTs are more focused on teacher centred learning as opposed to student centred learning where the teacher is the source of influence and information.

Although there were opportunities for reflective thinking when writing their journals, the reflective process seemed centred around their performance in class rather than the actual learning that takes place in their students. They seem to focus more on students 'accepting' and 'liking' what they taught. Therefore the focus on their own teaching and 'performance' in class can be described as an 'anticipatory emotion' (Hayes, 2003) where there is a mixture of anxiety and excitement about the classroom and the actual teaching situation. Interestingly, only about half of the respondents were confident about dealing with students and the activities that took place in class. Goh and Blake (2015) highlighted this dilemma noting that it stems from PSTs' lack of confidence to control their students often having to resort to discipline and raising their voices resulting in frustrations for both parties. This finding is not surprising given that PSTs are themselves evaluated by their supervisors and mentor teachers, hence the pressure is on them to give their best in the classroom. However, all this happens at the expense of the actual learning that takes place in the classroom.

\section{How do PSTs use reflective thinking to analyse their teaching practice?}

The respondents did not seem to be open to negative feedback given by students, they were looking more forward to the popularity and acceptance they could gain from students rather than learning from experience as a whole. The respondents were also reluctant to use negative feedback as a tool to help them grow their skills. While all the respondents seemed intent on writing their reflective journals, they did it more as an assignment rather than as a tool to help them analyse their teaching skills. About half of the respondents were also using videos of themselves teaching apart from reflective journals to help them analyse and improve their teaching skills. Although these PSTs perceived videotaping their lesson was helpful, there was no further elaboration on how it helped them with their teaching.

It is also interesting to note that about half of them were more interested in getting their supervisors' and mentors' observation feedback rather than viewing and analysing video tapes of their lessons. This shows a lack of confidence in the self-assessment process, requiring an authority figure to give affirmations, comments and guidance. Goh and Matthews (2011) noted that PSTs need the reinforcement and recognition given by their mentors to affirm their teaching abilities. It is important to note that all the respondents believed they had good teaching ability and were willing to learn from students' feedback. Hence the idea that reflective journals will stimulate self-discovery, teaching awareness and troubleshoot potential problems areas may not be as effective without the proper reinforcements and affirmations from mentors on the use of these journals as a tool for analysis of the teaching process. These journals will then be no more than a part of the coursework to be completed for a grade.

\section{Limitations}

The sample for this study is taken from one university in Malaysia which offers teacher education programmes for its students, the interpretive approach used in this study implies the interpretation of data that is not value free hence the results obtained are free from subjectivity. However, some of the results may be generalizable to some degree otherwise it will be pointless carrying out this study. Hence the results obtained may be applicable to other similar situations.

\section{Implication and Conclusions}

The results of this study seem to indicate that Malaysian PSTs may not know how to use reflective thinking to help them improve their teaching skills. They are more involved 
with ensuring that they are evaluated well by their mentors than what their students are learning during their lessons. Their perspective is more on gaining recognition from their mentors that they are carrying out their duties well as teachers than reflecting on their teaching to self-improve. Further to this, reflective thinking aids autonomous learning and through reflection PSTs are supposed to gain further insights into the progress of their own teaching and make adjustments to areas that appear weak. However, it may be challenging for Malaysian PSTs to transition to such autonomous learning as they are more accustomed to being closely guided by their supervisors and mentor teachers, although concerted efforts are being made by universities to encourage more student-centred learning.

The results of this study also indicate that reflective thinking has minimal influence on PSTs. Many of these PSTs are carrying out the process because it is built into the coursework and they have to fulfil the requirements of writing a reflective journal to complete their practicum. They prefer to get direct feedback from their mentors rather than analysing and critiquing their performance through these journals. There has also been no follow-up studies on whether the reflective thinking process introduced during the PSTs practicum is continually used during their actual teaching practice. The results of this study seem to suggest that these PSTs are more focused on the techniques of teaching and seldom reflect and more likely to follow orders which Choy and Oo (2012) defined as the introductory level of reflection.

The PSTs also appeared to be overly worried about making mistakes which suggests that if they actually carried out reflection of what they did in class, it is very minimal and mostly on the surface. Reflection if properly carried out will minimise errors in teaching (Lindh \& Thorgren, 2015; Roessger, 2014) as well as help them become active learners (Schon, 1987). This lack of reflective skills can be explained by the interdependent nature (Park, Uchida \& Kitayama, 2015) of these PSTs where they may be more focused on engagement with and acceptance by their social group. Hence, they prefer to get feedback from leaders of this group rather than coming to conclusions and insights about their teaching independently. These PSTs may not develop the necessary thinking skills that will enable them to effectively incorporate critical thinking and active learning into their classrooms.

If Malaysia is to realise the aspirations of the MEB, there will have to be changes and improvements in the teacher education programmes. Goh and Blake (2015) have highlighted the plight of PSTs during their practicum where many of them are not prepared to manage their classrooms or their students as they have to struggle with 'how' and 'what' to teach. Currently there is no definition of what is adequate in terms of the practicum experience other than the number of hours spent in the classroom. If reflective thinking is to play a part in the teaching experience of PSTs, there must also be clearer indicators of it taking place during the whole practicum process. Currently it is necessary for PSTs to write a reflective log of their teaching practicum but other than it being a part of the course requirement, the reflective process is not taken further to be incorporated into the actual teaching practice. Many practicing teachers in schools, still struggle with critical and higher order thinking (Othman \& Mohamad, 2014) in addition to having to deal with students from diverse backgrounds having a multitude of social problems (Kuldas et al, 2015). These PSTs can also benefit from having their reflective thinking skills enhanced which have been found to help with problem-solving especially if they are encouraged to be critical rather than just focus on the technical aspects when analysing their teaching (Yaacob et al., 2014).

\section{Acknowledgements}

This research work is supported by Tunku Abdul Rahman University College Internal Grant UC/1/G2019-00039. 


\section{Appendix 1: Interview Questions}

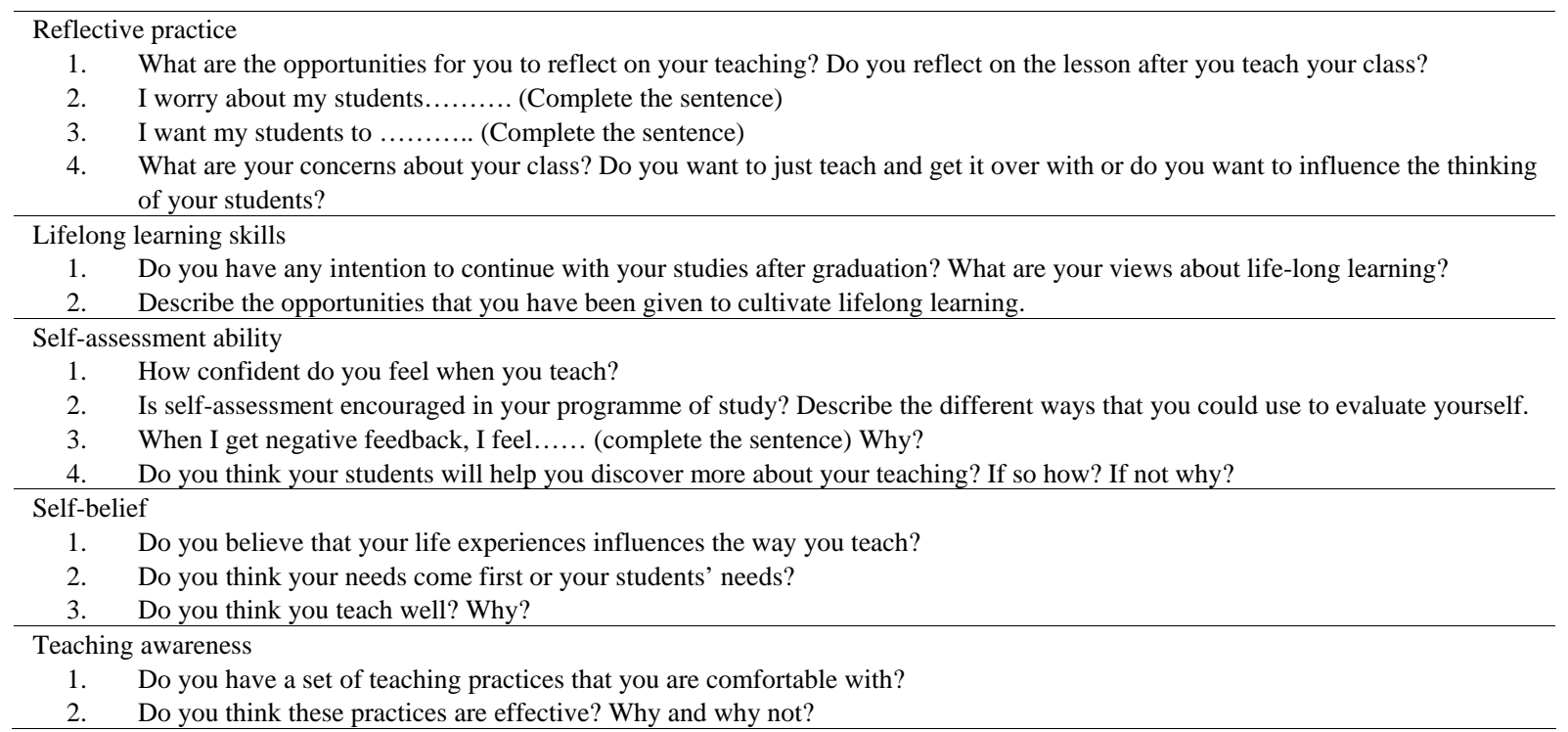

\section{REFERENCES}

[1] Barnhart, T., \& van Es, E. (2015). Studying teacher noticing: Examining the relationship among pre-service science teachers' ability to attend, analyze and respond to student thinking. Teaching and Teacher Education, 45, 83-93.

[2] Black, S. (2005). Teaching students to think critcally. The Education Digest, 70(6), 42-47.

[3] Bloom, B. S. (1956). Taxonomy of Educational Objectives. Boston: Allyn and Bacon.

[4] Brookfield, S. D. (1995). Becoming a critically reflective teacher. London: Jossey-Bass.

[5] Choy, S. C., \& Cheah, P. K. (2009). Teacher perception of crtitical thinking among studetns and its influence on higher education. International Journal of teaching and learning in Higher Education, 20 (2), 198-206.

[6] Choy, S. C., \& Oo, P. s. (2012). Reflective thinking and teaching practices: A precursor for incorporating critical thinking into the classroom. International Journal of Instruction, 5(1), 167-182.

[7] Choy, S. C., Yim, S. C., \& Tan, P. L. (2017). Students' perceptions of quality learning in a Malaysian university - A mixed method approach. Quality Assurance in education, https://doi.org/10.1108/QAE-12-2016-0088.

[8] Clara, M. (2014). What is reflection? Looking for clarity in an ambigious notion. Journal of Teacher Education, 66(3) 261271. DOI: $10.1177 / 0022487114552028$.

[9] Cohen, L., Manion, L., \& Morrison, K. (2000). Research Methods in Education. London: Routledge-Falmer.

[10] Dewey, J. (1963). Education and Experience. New York: Collier Books.
[11] DeWitt, D., Alias, N., \& Siraj, S. (2016). Problem solving strategies of malaysian secondary school teachers. Educational Technology to Improve Quality and Access of Education to Prosperous Society. (pp. 1-14). Bali: Universitas Negeri Jakarta.

[12] Ennis, R. (2011). Critical thinking: Reflection and perspective (Part 1). Inquiry: Critical thinking Across the Disciplines, 26 (1), 4-18.

[13] Felton, M. K., \& Kuhn, D. (2007). "How do I know?" The epistemological roots of critical thinking. Journal of Museum Education, 32 (2), 101-12.

[14] Goh, P. S., \& Blake, D. (2015). Teacher preparation in Malaysia: needed changes. Teaching in Higher Education, 20(5), 469-480.http://dx.doi.org/10.1080/13562517.2015.10 20780.

[15] Goh, P. S., \& Matthews, B. (2011). Listening to the concerns of student teachers In Malaysia during teaching practice . Australian Journal of Teacher Education, 36(3), 92-103.

[16] Hayden, H. E., \& Chiu, M. M. (2015). Reflective Teaching via a Problem Exploration-Teaching Adaptations-Resolution Cycle: A Mixed Methods Study of Preservice Teachers' Reflective Notes. Journal of Mixed Methods Research, 9(2) 133-153.

[17] Hayes, D. (2003). Emotional Preparation for Teaching: a case study about trainee teachers in England. Teacher Development, 7(2), 153-171.

[18] Kuhn, D. (2016). A role for reasoning in a dialogic approach to critical thinking. Topoi, 1-8.

[19] Kuldas, S., Hashim, S., \& Ismail, H. N. (2015). Malaysian adolescent students' needs for enhancing thinking skills, counteracting risk factors and demonstrating academic resilience. International Journal of Adolescence and Youth, 20(1), 32-47.doi:10.1080/02673843.2014.973890 .

[20] Larkin, M., Watts, S., \& Clifton, E. (2006). Giving voice and making sense in interpretive phenomenological analysis. 
Qualitative research in Psychology, 3, 102-120.

[21] Lindh, Ida, \& Thorgren, S. (2015). Critical event recognition: An extended view of reflective learning. Management Learning, 1-18.

[22] Ministry of Education Malaysia. (2013). Malaysia education blueprint (2013-2025) higher education. Putrajaya: Ministry of Education Malaysia.

[23] Nagappan, R. (2001). Language teaching and the enhancement of higher-order thinking skills. In W. A. Renadaya, \& N. A. Sunga, Language curriculum and instruction in multicultural societies - Anthology series 42. Singapore: SEAMEO Regional Language centre.

[24] Nair, P. G.-1. (2017). Owning the classroom: Student teachers' experiences and concerns during practicum. The English Teacher, 46(3), 142-159.

[25] Ong, E. T. (2006). The Malaysian Smart Schools Project: An Innovation to Address Sustainability. Learning Together for Tomorrow: Education for Sustainable Development. Bangkok: UNESCO-APEID.

[26] Osterman, K. F., \& Kottkamp, R. B. (1993). Reflective practice for educators. London: Cowin Press.

[27] Othman, N., \& Mohamad, K. A. (2014). Thinking skill education and transformational progress in Malaysia. International Education Studies, 7(4), 27--32. doi:10.5539/ies.v7n4p27.

[28] Park, J., Uchida, Y., \& Kitayama, S. (2015). Cultural variation in implicit independence: An extension of Kitayama et al. (2009). International Journal of Psychology, 1-10. DOI: 10.1002/ijop.12157.

[29] Rodgers, C. (2002). Defining reflection: Another look at John Dewey and reflective thinking. Teachers College Record, 104(4), 842-866.

[30] Roessger, K. M. (2014). The effects of reflective activites on skill adaptation in a work-related instrumental learning setting. Adult Education Quarterly, 64(4), 323-344.

[31] Sahin, G. G., \& Ovez, F. T. (2012). An investigation of prospective teachers' reflective thinking tendency. Procedia-Social and Behavioral Sciences, 55, 568 - 574.

[32] Schon, D. A. (1987). Education the reflective practioner. San Francisco: Jossey-Bass.

[33] Sparks-Langer, G. M., \& Colton, B. (1991). Synthesis of research on teachers' reflective thinking. Educational Leadership, 3, 37-44.

[34] Wong, Y. M., Mansor, R., \& Samsudin, S. (2015). The challenge of producing progressive teachers in Malaysia: A case study of reflective writings among UPSI student teachers. GEOGRAFIA Online Malaysian Journal of Society and Space, 11(7), 21 -32.

[35] Wragg, E. (1984). Conducting and analysing interviews. In J. Bell, A. Bush, J. Fox, J. Goodey, \& S. Goulding (Eds.), Conducting small scale investiagations into educational managment. London: Harper \& Row.

[36] Yaacob, A., Walters, L. M., Ali, R. M., Abdullah, S. S., \& Walters, T. (2014). Reflecting on Malaysian teacher trainee's journal. Malaysian Journal of Learning and Instruction, 11, $1-21$. 